\title{
Current clinical application of deep-brain stimulation for essential tremor
}

\author{
This article was published in the following Dove Press journal: \\ Neuropsychiatric Disease and Treatment \\ 29 November 2013 \\ Number of times this article has been viewed
}

\section{Amit Chopra \\ Bryan T Klassen \\ Matt Stead}

Department of Neurology, Mayo Clinic, Rochester, MN, USA
Correspondence: Matt Stead

Department of Neurology,

Mayo Clinic, 200 Ist Street Southwest,

Rochester, MN 55905, USA

Email squire.stead@mayo.edu
Background: Deep-brain stimulation (DBS) is an established treatment for medically refractory essential tremor (ET). This article reviews the current evidence supporting the efficacy and safety of DBS targets, including the ventral intermediate (VIM) nucleus and posterior subthalamic area (PSA) in treatment of ET.

Methods: A structured PubMed search was performed through December 2012 with keywords "deep brain stimulation (DBS)," "essential tremor (ET)," "ventral intermediate (VIM) nucleus," "posterior subthalamic area (PSA)," "safety," and "efficacy."

Results: Based on level IV evidence, both VIM and PSA DBS targets appear to be safe and efficacious in ET patients in tremor reduction and improving activities of daily living, though the literature on PSA DBS is limited in terms of bilateral stimulation and long-term follow-up. DBS-related adverse effects are typically mild and stimulation-related. Hardware-related complications after DBS may not be uncommon, and often require additional surgical procedures. Few studies assessed quality-of-life and cognition outcomes in ET patients undergoing DBS stimulation.

Conclusion: DBS appears to be a safe and effective treatment for medically refractory ET. More systematic studies comparing VIM and PSA targets are needed to ascertain the most safe and effective DBS treatment for medically refractory ET. More research is warranted to assess quality-of-life and cognition outcomes in ET patients undergoing DBS.

Keywords: deep-brain stimulation (DBS), essential tremor (ET), ventral intermediate (VIM) nucleus, posterior subthalamic area (PSA), safety, efficacy

\section{Introduction}

Essential tremor (ET) is the most common movement disorder, and is characterized by $4-12 \mathrm{~Hz}$ postural and kinetic tremor involving the arms and less commonly the head, lower extremities, and voice. ${ }^{1}$ The estimated prevalence of ET is $0.4 \%-3.9 \%,{ }^{2}$ with even higher prevalence $(4.6 \%)$ in people over 65 years of age. ${ }^{3}$ ET symptoms, thought to be benign in nature, often cause embarrassment and can potentially lead to serious disability in a subset of ET patients. ${ }^{4,5}$

The first-line treatment of ET is pharmacologically based and comprised of trials of medications, including propranolol and primidone, ${ }^{6}$ though these medications tend to lose efficacy over time and are limited by adverse effects. ${ }^{1}$ Second-line treatments include trial of additional pharmacological agents, including anticonvulsants, neuroleptics, antidepressants, and botulinum toxin. ${ }^{6}$ Overall, the best medication outcomes tend to show tremor reduction in only approximately $50 \%$ of ET patients. ${ }^{7}$ 
Once medical treatments fail, ET patients are considered for surgical treatments, including stereotactic standard thalamotomy, gamma-knife thalamotomy, and deep-brain stimulation (DBS). During the performance of thalamotomies for ET in the 1960s, investigators found that intraoperative high-frequency stimulation $(100 \mathrm{~Hz})$ of the ventral intermediate (VIM) nucleus of the thalamus dramatically reduced tremor, ${ }^{8,9}$ which eventually led to clinical application of thalamic DBS in treatment of ET by Benabid and colleagues. ${ }^{10}$

Currently, DBS is a US Food and Drug Administration (FDA)-approved treatment for management of medically refractory ET. The DBS system comprises three components: implanted pulse generator, lead, and an extension. Despite the established efficacy of DBS in treatment of ET over the last two decades, the exact mechanism of action of DBS remains unclear. ${ }^{11}$ The efficacy of DBS has been noted to be comparable to thalamotomy; ${ }^{12}$ however, DBS has essentially replaced ablation surgical procedures, due to its efficacy, safety, and relative reversibility of the adverse effects in the treatment of ET. ${ }^{13}$

For treatment of medically refractory ET, the VIM nucleus of the thalamus is the most common DBS target, whereas evidence is growing to support the efficacy of DBS of the posterior subthalamic area (PSA). This article reviews the systematic evidence focusing on efficacy and safety outcomes of VIM and PSA targets in DBS treatment of medically refractory ET.

\section{Methods}

A structured PubMed search was performed through December 2012 with the keywords "deep brain stimulation (DBS)," "essential tremor (ET)," "ventral intermediate (VIM) nucleus," "posterior subthalamic area (PSA)," "safety," and

Table I Efficacy outcomes of VIM DBS in essential tremor

\begin{tabular}{|c|c|c|c|c|}
\hline Study & ET patients (n) & Target & Follow-up & Outcome/improvement \\
\hline Carpenter et $\mathrm{al}^{14}$ & $\mathrm{n}=7$ & $\begin{array}{l}5 \text { unilateral, } 2 \\
\text { bilateral VIM }\end{array}$ & 18 months & $\begin{array}{l}\text { DBS on/off; } 4 / 7 \text { patients showed reduction in voice } \\
\text { tremor }\end{array}$ \\
\hline Lyons et al ${ }^{15}$ & $\mathrm{n}=22$ & Unilateral VIM & II months & $\begin{array}{l}\text { DBS on/off; } 57.9 \% \text { (self-rated TADLS), } 39.3 \% \\
\text { (overall tremor) }(P<0.001)\end{array}$ \\
\hline Koller et al ${ }^{16}$ & $\mathrm{n}=38$ & Unilateral VIM & $3,6,12$ months & $\begin{array}{l}\text { DBS on/off; } 75 \% \text { (head tremor); significantly } \\
\text { improved overall tremor }(P<0.01)\end{array}$ \\
\hline Obwegeser et al ${ }^{17}$ & $\mathrm{n}=27$ & $\begin{array}{l}14 \text { unilateral and } \\
13 \text { bilateral VIM }\end{array}$ & 12 months & $\begin{array}{l}\text { DBS on/off; unilateral - } 82 \% \text { (arm), 38\% (head), } \\
\text { voice none; bilateral - 95\% (head), } 83 \% \text { (voice) }\end{array}$ \\
\hline Koller et $\mathrm{al}^{18}$ & $\mathrm{n}=49$ & Unilateral VIM & $40.2 \pm 14.7$ months & DBS on/off; $78.5 \%$ (overall tremor) $(P<0.01)$ \\
\hline Hariz et al ${ }^{19}$ & $\mathrm{n}=27$ & $\begin{array}{l}\text { Unilateral and } \\
\text { bilateral VIM }\end{array}$ & 12.5 months & DBS before/after; $47.4 \%$ (tremor) $(P<0.000 \mathrm{I})$ \\
\hline Sydow et $\mathrm{al}^{20}$ & $n=19$ & $\begin{array}{l}12 \text { unilateral and } \\
7 \text { bilateral VIM }\end{array}$ & 6 years & $\begin{array}{l}\text { DBS on/off; significant improvement in overall } \\
\text { tremor and } A D L(P<0.00 I) \text {; no improvement in } \\
\text { voice tremor }\end{array}$ \\
\hline Rehncrona et $\mathrm{al}^{21}$ & $\mathrm{n}=19$ & $\begin{array}{l}17 \text { unilateral and } \\
2 \text { bilateral VIM }\end{array}$ & 78 months & $47.1 \%$ (overall tremor) \\
\hline Putzke et $\mathrm{al}^{22}$ & $\mathrm{n}=22$ & $\begin{array}{l}29 \text { unilateral and } \\
23 \text { bilateral VIM }\end{array}$ & $\begin{array}{l}\text { I, } 3,12 \text { months; } \\
2 \text { and } 3 \text { years }\end{array}$ & $\begin{array}{l}\text { DBS on/off; significant improvement in overall } \\
\text { tremor and ADL }(P<0.05)\end{array}$ \\
\hline Lee and Kondziolka ${ }^{23}$ & $n=19$ & Unilateral VIM & 27 months & $\begin{array}{l}\text { DBS before/after; } 75.8 \% \text { (tremor) and } 64.3 \% \\
\text { (handwriting) }(P<0.005)\end{array}$ \\
\hline Pahwa et $\mathrm{al}^{24}$ & $\mathrm{n}=26$ & $\begin{array}{l}18 \text { unilateral and } \\
8 \text { bilateral VIM }\end{array}$ & 5 years & $\begin{array}{l}\text { DBS on/off; unilateral - } 75 \% \text { (contralateral arm); } \\
\text { bilateral - } 65 \% \text { (left arm), } 85 \% \text { (right arm); }(P<0.0 \text { I) }\end{array}$ \\
\hline Blomstedt et $\mathrm{a}^{25}$ & $\mathrm{n}=19$ & Unilateral VIM & $86 \pm 9$ months & $\begin{array}{l}\text { DBS before/after; } 60.3 \% \text { (hand tremor), } 35.4 \% \\
\text { (hand function) }\end{array}$ \\
\hline Pilitsis et $\mathrm{al}^{26}$ & $\mathrm{n}=26$ & $\begin{array}{l}22 \text { unilateral and } \\
4 \text { bilateral }\end{array}$ & 40 months & $\begin{array}{l}\text { DBS before/after; } 75.3 \% \text { (tremor), } 73.8 \% \\
\text { (handwriting) }\end{array}$ \\
\hline Zhang et $\mathrm{a}^{27}$ & $n=34$ & $\begin{array}{l}23 \text { unilateral and } \\
\text { I I bilateral VIM }\end{array}$ & 56.9 months & $\begin{array}{l}\text { DBS before/after; } 80.4 \% \text { (tremor) and } 69.7 \% \\
\text { (handwriting) }(P<0.00 I)\end{array}$ \\
\hline Nazzaro et $\mathrm{al}^{28}$ & $\mathrm{n}=91$ & Unilateral VIM & 9 years & $\begin{array}{l}\text { DBS before/after; } 31 \% \text { (tremor), } 36.9 \% \text { (ADL), } \\
10.3 \% \text { (QOL at } 4 \text { years) }\end{array}$ \\
\hline de Oliviera et $\mathrm{al}^{29}$ & $\mathrm{n}=26$ & $\begin{array}{l}19 \text { unilateral and } \\
7 \text { bilateral VIM }\end{array}$ & $4 I$ months & $\begin{array}{l}\text { DBS on/off; significant improvement in overall } \\
\text { tremor and QOL }\end{array}$ \\
\hline
\end{tabular}

Abbreviations: $\mathrm{ET}$, essential tremor; VIM, ventrointermediate nucleus of thalamus; ADL, activities of daily living; TADLS, tremor activities of daily living scale; QOL, quality of life; DBS, deep-brain stimulation. 
Table 2 Efficacy outcomes of PSA DBS in essential tremor

\begin{tabular}{|c|c|c|c|c|}
\hline Study & ET patients (n) & Target & Follow-up & Outcome/improvement \\
\hline Murata et $\mathrm{al}^{30}$ & $\mathrm{n}=8$ & $\begin{array}{l}\text { Unilateral } \mathrm{Zi} \\
\text { and prelemniscal radiation }\end{array}$ & 42 months & $81 \%$ (contralateral tremor) \\
\hline Plaha et $\mathrm{a}^{31}$ & $\mathrm{n}=4$ & Bilateral PSA & 12 months & DBS before/after; $80 \%$ (tremor) \\
\hline Blomstedt et $\mathrm{a}^{32}$ & $\mathrm{n}=2 \mathrm{l}$ & $\begin{array}{l}\text { PSA; } 19 \text { unilateral } \\
\text { and } 2 \text { bilateral }\end{array}$ & I year & $\begin{array}{l}\text { DBS before/after and DBS on/off; 95\% } \\
\text { (upper-extremity tremor); } 87 \% \text { (hand } \\
\text { function); } 66 \% \text { (ADL) }\end{array}$ \\
\hline Plaha et $\mathrm{al}^{33}$ & $\mathrm{n}=15$ & cZi; bilateral & $\begin{array}{l}31.7 \pm \\
28.6 \text { months }\end{array}$ & $\begin{array}{l}\text { DBS before/after and DBS on/off; } 73.8 \% \\
\text { (overall tremor); } 60.1 \% \text { (hand function); } \\
80 \% \text { (ADL); } 23.7 \% \text { (QOL) }\end{array}$ \\
\hline Blomstedt et al ${ }^{34}$ & $\begin{array}{l}n=5 \text {; previously } \\
\text { failed VIM }\end{array}$ & $c Z i$ & $\mathrm{I}-2$ years & $57 \%(\mathrm{cZi})$ versus $25 \%(\mathrm{VIM})$ \\
\hline Fytagoridis et $\mathrm{a}^{35}$ & $\mathrm{n}=18$ & $\begin{array}{l}\text { cZi; } 16 \text { unilateral } \\
\text { and } 2 \text { bilateral }\end{array}$ & 4 years & $\begin{array}{l}\text { DBS before/after and DBS on/off; } 51.4 \% \\
\text { (total tremor); } 89.4 \% \text { (upper-extremity } \\
\text { tremor); } 78 \% \text { (hand function) }\end{array}$ \\
\hline Sandvik et $\mathrm{a}^{36}$ & $\mathrm{n}=16$ & $\begin{array}{l}\text { cZi; } 14 \text { unilateral } \\
\text { and } 2 \text { bilateral }\end{array}$ & 12 months & $\begin{array}{l}\text { DBS before/after; } 95 \% \text { (tremor); } 78 \% \\
\text { (hand function); } 71 \% \text { (ADL); nonsignificant } \\
\text { for modest changes in QOL }\end{array}$ \\
\hline
\end{tabular}

Abbreviations: ET, essential tremor; PSA, posterior subthalamic area; $c Z i$, caudal zona incerta; VIM, ventrointermediate nucleus of thalamus; ADL, activities of daily living; QOL, quality of life; DBS, deep-brain stimulation; Zi, zona incerta.

"efficacy". In this review, we have included original research studies published in the English medical literature focusing on DBS treatment in ET patients only. A total of 17 studies for VIM DBS ${ }^{14-29}$ and seven studies for PSA DBS ${ }^{30-36}$ were included in this review.

\section{Results}

Tables 1 and 2 summarize the studies assessing efficacy outcomes of VIM and PSA DBS targets in medically refractory ET patients.

\section{Discussion}

\section{Ventral intermediate nucleus of thalamus DBS}

Based on direct and indirect neurophysiological studies, it has been suggested that a neuronal network involving the thalamus (especially VIM), the sensorimotor cortex, the inferior olivary nuclei, and cerebellum may be responsible in the production of ET. ${ }^{37}$ Animal studies further support this hypothesis, as harmaline, a central nervous stimulant, has been used to induce a reversible essential tremor-like state characterized by abnormal tremor-specific oscillations in the olivocerebellar pathway. ${ }^{37}$

VIM is thought to correspond to the ventral lateral posterior nucleus (VLp) in the nomenclature used in the animal literature..$^{38}$ According to animal studies, VLp has been shown to have connectivity to the primary motor corte ${ }^{39}$ and to receive cerebellar input, ${ }^{40}$ and these findings have been replicated in human subjects using noninvasive diffusion tactography. ${ }^{41}$
The posterior part of the ventral lateral anterior nucleus (VLa), which lies directly anterior to the VLp, receives pallidal afferents. ${ }^{41}$ Given their close proximity, it is likely that stimulation of the VLa may contribute to modulation of the tremor network in VIM DBS. ${ }^{41}$

VIM DBS appears to be an essentially safe treatment, with few serious adverse events likely not affecting its longterm outcomes. ${ }^{42}$ VIM DBS is considered to be the surgical target of choice for treatment of medically refractory ET. ${ }^{7}$ The optimal electrode location for DBS in ET corresponds to the anterior margin of the VIM. It has been suggested that leads located $>2 \mathrm{~mm}$ (in the plane of the commissures) from the optimal coordinates are more likely to be associated with poor tremor control than leads $<2 \mathrm{~mm}$ from the optimal location. ${ }^{43}$

The authors have reported postsurgical follow-up duration for VIM DBS patients ranging from 3 months to a maximum of 9 years. Change in the Fahn-Tolosa-Marin (FTM) tremor-rating scale score is the primary outcome measure in most of these studies, except for two studies using the essential tremor-rating scale (ETRS) as the primary outcome measure. ${ }^{20,21}$ The assessors reportedly did blinded assessments only in five of 17 studies. . $^{15,16,18,19,21}$

In this review, the authors report significant improvement (40\%-85\%) in overall ET symptoms postoperatively, with these improvements being generally sustained during long-term follow-up after VIM DBS. Where reported, significant improvement in tremor-rating scores (FTM/ ETRS) was noted with DBS switched on compared to 
scores with DBS off and with the baseline measurements. Significant improvement in hand function, handwriting, and activities of daily living has been noted in ET, along with improvement in tremor symptoms, after VIM DBS in the majority of studies. ${ }^{15,16,20,22,23,26-28}$ Sustained improvements in quality-of-life (QOL) outcomes and patient satisfaction at long-term follow-up after VIM DBS have been assessed in four of 17 studies. ${ }^{19,27-29}$ One of the studies assessing QOL outcomes suggests that patient satisfaction may be directly proportional to improvements in activities of daily living and tremor control in ET patients undergoing VIM DBS. ${ }^{29}$

The effect of VIM DBS specifically on head-tremor symptoms has been established in two of 17 studies, ${ }^{16,17}$ with bilateral VIM DBS being more effective than unilateral stimulation in one study. ${ }^{17}$ Voice-tremor outcomes in ET patients after VIM DBS stimulation seem to be somewhat mixed. According to one study including seven ET patients (five unilateral, two bilateral VIM DBS), voice tremor improved significantly only in patients who had severe symptoms, and there were no notable differences between patients who underwent unilateral versus bilateral VIM DBS. ${ }^{14}$ Significant improvement in voice tremor $(83 \%)$ in patients undergoing bilateral VIM DBS stimulation compared to unilateral stimulation was observed in another study, ${ }^{17}$ whereas no improvement in voice tremor was noted in 19 ET patients (twelve unilateral, seven bilateral) postoperatively and at 6 years after VIM DBS stimulation in another. ${ }^{20}$

The most common adverse events associated with VIM DBS include paresthesias, dysarthria, and disequilibrium. These side effects are typically mild and generally amenable to changes in DBS parameters. Dysarthria and disequilibrium have been more commonly associated with bilateral VIM DBS stimulation. Serious adverse events, such as stroke and seizures, have been reported occasionally after VIM DBS surgery. DBS device-related complications, including infection, lead fracture, and skin erosion, were not uncommon and often required further surgery, thus increasing the health care and cost burden of the DBS procedure. One of the studies has reported the overall hardware-related complication rate to be $23.5 \%{ }^{27}$

\section{Posterior subthalamic area DBS}

Another emerging DBS target for ET, PSA, is bound anteriorly by the posterior border of the subthalamic nucleus, superiorly by the ventral thalamic nuclei, inferiorly by the dorsal border of the substantia nigra, posteriorly by the medial lemniscus, posteromedially by the anterolateral border of the red nucleus, posterolaterally by the ventrocaudal nucleus, and laterally by the posterior limb of the internal capsule.

PSA consists of the zona incerta $(\mathrm{Zi})$ and prelemniscal radiation (Raprl). The $\mathrm{Zi}$ lies dorsal and posterior to the subthalamic nucleus (STN) and anatomically consists of a caudal part (cZi) and a rostral part. Its caudal or motor component lies posteromedial to the STN, and its rostral component extends over the dorsal and medial surface of the STN. ${ }^{44,45}$ The Raprl is a fiber bundle lying posterior to the STN, and separated from it by the intervening $\mathrm{Zi}$. It contains fibers from the mesencephalic reticular formation that projects to the thalamus as well as ascending cerebellothalamic fibers. ${ }^{46}$

The mechanism of tremor suppression by DBS in PSA (predominantly cZi) is not entirely clear. ${ }^{46}$ The $\mathrm{Zi}$ is a heterogeneous nucleus that lies at the base of the dorsal thalamus and is considered to be an extension of the reticular/thalamic nucleus. It receives afferents from the globus pallidus internus, the substantia nigra reticulata $(\mathrm{SNr}),{ }^{44,47,48}$ the ascending reticular activating system, ${ }^{47-49}$ the interpositus nucleus of the cerebellum, and also the motor, associative, and limbic areas of the cerebral cortex. ${ }^{45}$ It sends efferents to the centromedian and parafascicular nuclei, ${ }^{50-52}$ the ventral anterior nucleus and the ventral lateral nucleus of the thalamus, ${ }^{53}$ the midbrain extrapyramidal area and the medial reticular formation, the globus pallidus internus and substantia nigra reticulate, ${ }^{44}$ the interpositus nucleus of the cerebellum, the inferior olive, and the cerebral cortex..$^{54,55}$

Abnormal synchronization of neuronal firing in the basal ganglia thalamocortical loop, the cerebellar thalamocortical loop, or both loops has been considered to be an underlying mechanism in a range of neurological disorders associated with tremor. ${ }^{56} \mathrm{cZi}$ proves to be an effective target for the surgical control of all forms of tremor, due to its unique GABAergic connections with both the basal ganglia and cerebellar thalamocortical loops. Additionally, stimulation of the $\mathrm{Zi}$ is likely to suppress the tremor by overriding the oscillations in the brain stem-motor effectors through which tremor oscillation may be transmitted. ${ }^{56}$

In this review, PSA DBS has been targeted mainly in a unilateral fashion, with fewer patients undergoing bilateral stimulation. In five of seven studies, ${ }^{33-36}$ DBS targeting was more specific in the PSA region with stimulation of the caudal cZi only. The follow-up duration for PSA DBS patients ranges from 3 months to 4 years. Generally, PSA/cZi DBS stimulation has been associated with significant improvements in tremor (50\%-95\%) in both short-term and long-term follow-up. One study $(n=5)$ evaluating the efficacy of cZi DBS in patients with failed VIM DBS reported improvement in overall tremor 
with cZi DBS (57\%) compared to VIM DBS (25\%), although considerable residual tremor was noted in patients with late failure of VIM. ${ }^{34}$ Improvements in hand function and activities of daily living have been reported with PSA DBS in two of seven studies. ${ }^{32,35}$ The QOL outcomes with PSA DBS are somewhat mixed, as one study primarily including unilateral cZi target showed nonsignificant-to-modest improvements in $\mathrm{QOL}^{36}$ compared to significant improvements associated with bilateral cZi stimulation. ${ }^{33}$

The adverse effects associated with PSA DBS are usually mild, and include transient paresthesias, dysphasia, and disequilibrium. PSA DBS stimulation generally lacks lasting dysarthria and disequilibrium, in contrast to VIM DBS, particularly bilateral VIM DBS. This may be explained by the fact that the cZi DBS only overrides tremor oscillations without interrupting patterns of information related to fine movements of vocal cords and proprioceptive sensation. ${ }^{56}$ Rare serious adverse events, including transient mild hemiparesis and seizure, have been reported with PSA DBS. Device-related complications such as infection have been less frequently reported with PSA DBS. However, it must be noted that the studies on PSA DBS in ET patients are still very limited compared to VIM DBS.

\section{VIM versus PSA DBS}

There are few studies comparing VIM and PSA targets for DBS treatment of ET. One retrospective study ${ }^{57}$ including 36 ET patients (17 VIM/19 PSA) with 44 DBS electrodes reported that the electrode contact providing the best effect in individual tremor control, measured by the ETRS, was located predominantly in the $\mathrm{Zi}$ or Raprl (54\%) compared to VIM (12\%). Another prospective study including $68 \mathrm{ET}$ patients (34 VIM/34 PSA) reported improvement in hand tremor and hand function (measured by ETRS) by $70 \%$ in the VIM group compared to $89 \%$ in the PSA group, ${ }^{58}$ though the duration of follow-up varied between the two groups, with mean follow-up of 1 year for PSA DBS compared to $28 \pm 24$ months' follow-up for VIM DBS, and this may have potentially affected the outcomes. In this study, the efficacy of DBS in ET was not related to age, sex, or the severity of tremor, although patients with a more severe tremor at baseline had a higher degree of residual tremor on stimulation.

Additionally, PSA DBS has been proven to be effective in tremor suppression for those tremors difficult to be adequately controlled by VIM DBS, such as proximal postural tremor, distal intention tremor, and cerebellar outflow tremor associated with ET and multiple sclerosis. ${ }^{58}$ However, to date, there have been no randomized controlled trials comparing the safety and efficacy of VIM and PSA DBS in ET.

\section{DBS patient selection for ET}

All ET patients with medically refractory tremor should be considered for DBS after failed trials of medications that have proven to be effective in ET based on randomized controlled studies. ${ }^{11}$ Elderly patients should be counseled about increased DBS-related surgical risks and their ability to consent for the procedure, particularly those with progressive memory dysfunction, should be investigated carefully.

Few studies report no overall change in cognitive functioning following VIM DBS. One study looking at cognitive outcomes in ET patients at 1-year follow-up reported no overall deleterious effects of unilateral VIM DBS on cognition, although preoperative verbal fluency diminution was noted be a predisposing factor toward further decline in verbal fluency after DBS. ${ }^{59}$ In regard to impact of DBS of PSA region on cognition, a recent study reported a tendency toward an immediate and mostly transient postoperative decline in verbal fluency following cZi DBS for ET; however, this decline can be more pronounced and sustained over time in a subset of patients. ${ }^{60}$ More systematic research is needed to assess the short- and long-term cognitive outcomes comparing unilateral and bilateral VIM/PSA DBS stimulation, particularly in elderly patients at higher risk of cognitive decline.

\section{DBS treatment failure}

DBS is generally an effective treatment for medically refractory ET, although treatment failure may occur in a subset of patients. Treatment failure may be seen in patients who receive no benefit immediately after surgery and those with good benefit initially, but tremor gradually returns after DBS surgery. ${ }^{27}$ The initial nonresponse is more likely to be caused by suboptimal DBS electrode placement, and reimplantation of the DBS electrodes for optimal targeting should be considered in such cases. ${ }^{27}$ The gradual loss of DBS effect over time is more complicated, and may be explained by progression of the ET and the phenomenon of tolerance. Given the slow progressive characteristics of ET and relatively stable stimulation-off symptoms even several years after DBS surgery, the role of disease progression in treatment failure after DBS is currently being debated. ${ }^{27}$

Compared to PSA DBS, tolerance is not uncommon in ET patients undergoing VIM DBS, as evidenced by a gradual increase of DBS voltage $(>3.6 \mathrm{~V})$ during long-term programming. ${ }^{25,26,61}$ Strategies including lower DBS voltage settings and turning the DBS stimulator off during sleeping 
hours might be helpful in patients experiencing tolerance. ${ }^{25}$ Even thalamotomy may be considered as a salvage treatment option in some patients with loss of efficacy of DBS due to tolerance. $^{62}$

\section{Conclusion}

In summary, DBS of the VIM and PSA regions appears to be a safe and effective treatment for medically refractory ET. More systematic studies comparing VIM and PSA targets are needed to ascertain the most safe and effective DBS treatment for medically refractory ET. More studies are needed to assess QOL and cognition outcomes in ET patients undergoing DBS.

\section{Disclosure}

The authors report no conflicts of interest in this work.

\section{References}

1. Zappia M, Albanese A, Bruno E, et al. Treatment of essential tremor: a systematic review of evidence and recommendations from the Italian Movement Disorders Association. J Neurol. 2013:260(3):714-740.

2. Louis ED, Ottman R, Hauser WA. How common is the most common adult movement disorder? Estimates of the prevalence of essential tremor throughout the world. Mov Disord. 1998;13(1):5-10.

3. Louis ED. Clinical practice. Essential tremor. $N$ Engl J Med. 2001; 345(12):887-891.

4. Koller W, Biary N, Cone S. Disability in essential tremor: effect of treatment. Neurology. 1986;36(7):1001-1004.

5. Busenbark KL, Nash J, Nash S, Hubble JP, Koller WC. Is essential tremor benign? Neurology. 1991;41(12):1982-1983.

6. Deuschl G, Koller WC. Introduction. Essential tremor. Neurology. 2000;54(11 Suppl 4):S1

7. Lyons KE, Pahwa R. Deep brain stimulation and essential tremor. J Clin Neurophysiol. 2004;21(1):2-5.

8. Hassler R, Riechert T, Mundiger F, Umbach W, Ganglberger JA. Physiological observations in stereotaxic operations in extrapyramidal motor disturbances. Brain. 1960;83(2):337-350.

9. Ohye C, Kubota K, Hongo T, Nagao T, Narabayashi H. Ventrolateral and subventrolateral thalamic stimulation. Motor effects. Arch Neurol. 1964;11:427-434.

10. Benabid AL, Pollak P, Gao D, et al. Chronic electrical stimulation of the ventralis intermedius nucleus of the thalamus as a treatment of movement disorders. J Neurosurg. 1996;84(2):203-214.

11. Hu W, Klassen BT, Stead M. Surgery for movement disorders. J Neurosurg Sci. 2011;55(4):305-317.

12. Schuurman PR, Bosch DA, Bossuyt PM, et al. A comparison of continuous thalamic stimulation and thalamotomy for suppression of severe tremor. N Engl J Med. 2000;342(7):461-468.

13. Pahwa R, Lyons KE, Wilkinson SB, et al. Comparison of thalamotomy to deep brain stimulation of the thalamus in essential tremor. Mov Disord. 2001;16(1):140-143.

14. Carpenter MA, Pahwa R, Miyawaki KL, Wilkinson SB, Searl JP, Koller WC. Reduction in voice tremor under thalamic stimulation. Neurology. 1998;50(3):796-798.

15. Lyons KE, Pahwa R, Busenbark KL, Troster AI, Wilkinson S, Koller WC. Improvements in daily functioning after deep brain stimulation of the thalamus for intractable tremor. Mov Disord. 1998;13(4):690-692.

16. Koller WC, Lyons KE, Wilkinson SB, Pahwa R. Efficacy of unilateral deep brain stimulation of the VIM nucleus of the thalamus for essential head tremor. Mov Disord. 1999;14(5):847-850.
17. Obwegeser AA, Uitti RJ, Turk MF, Strongosky AJ, Wharen RE. Thalamic stimulation for the treatment of midline tremors in essential tremor patients. Neurology. 2000;54(12):2342-2344.

18. Koller WC, Lyons KE, Wilkinson SB, Troster AI, Pahwa R. Long-term safety and efficacy of unilateral deep brain stimulation of the thalamus in essential tremor. Mov Disord. 2001;16(3):464-468.

19. Hariz GM, Lindberg M, Bergenheim AT. Impact of thalamic deep brain stimulation on disability and health-related quality of life in patients with essential tremor. J Neurol Neurosurg Psychiatry. 2002;72(1):47-52.

20. Sydow O, Thobois S, Alesch F, Speelman JD. Multicentre European study of thalamic stimulation in essential tremor: a six year follow up. J Neurol Neurosurg Psychiatry. 2003;74(10):1387-1391.

21. Rehncrona S, Johnels B, Widner H, Tornqvist AL, Hariz M, Sydow O. Long-term efficacy of thalamic deep brain stimulation for tremor: double-blind assessments. Mov Disord. 2003;18(2): $163-170$

22. Putzke JD, Uitti RJ, Obwegeser AA, Wszolek ZK, Wharen RE. Bilateral thalamic deep brain stimulation: midline tremor control. J Neurol Neurosurg Psychiatry. 2004;76(5):684-690.

23. Lee JYK, Kondziolka D. Thalamic deep brain stimulation for management of essential tremor. J Neurosurg. 2005;103(3):400-403.

24. Pahwa R, Lyons KE, Wilkinson SB, et al. Long-term evaluation of deep brain stimulation of the thalamus. $J$ Neurosurg. 2006;104(4): 506-512.

25. Blomstedt P, Hariz GM, Hariz MI, Koskinen LOD. Thalamic deep brain stimulation in the treatment of essential tremor: a long-term follow-up. Br J Neurosurg. 2007;21(5):504-509.

26. Pilitsis JG, Metman LV, Toleikis JR, Hughes LE, Sani SB, Bakay RAE. Factors involved in long-term efficacy of deep brain stimulation of the thalamus for essential tremor. J Neurosurg. 2008;109(4):640-646.

27. Zhang K, Bhatia S, Oh MY, Cohen D, Angle C, Whiting D. Long-term results of thalamic deep brain stimulation for essential tremor. J Neurosurg. 2009;112(6):1271-1276.

28. Nazzaro JM, Pahwa R, Lyons KE. Long-term benefits in quality of life after unilateral thalamic deep brain stimulation for essential tremor. J Neurosurg. 2012;117(1):156-161

29. de Oliveira TH, Ginsberg MR, Cooper S, et al. Long-term effects of deep brain stimulation for essential tremor with subjective and objective quantification via mailed-in questionnaires. Stereotact Funct Neurosurg. 2012;90(6):394-400.

30. Murata JI, Kitagawa M, Uesugi H, et al. Electrical stimulation of the posterior subthalamic area for the treatment of intractable proximal tremor. J Neurosurg. 2003;99(4):708-715.

31. Plaha P, Patel NK, Gill SS. Stimulation of the subthalamic region for essential tremor. J Neurosurg. 2004;101(1):48-54.

32. Blomstedt P, Sandvik U, Tisch S. Deep brain stimulation in the posterior subthalamic area in the treatment of essential tremor. Mov Disord. 2010;25(10):1350-1356.

33. Plaha $P$, Javed S, Agombar D, et al. Bilateral caudal zona incerta nucleus stimulation for essential tremor: outcome and quality of life. J Neurol Neurosurg Psychiatry. 2011;82(8):899-904.

34. Blomstedt P, Lindvall P, Linder J, Olivecrona M, Forsgren L, Hariz MI. Reoperation after failed deep brain stimulation for essential tremor. World Neurosurg. 2012;78(5):554. e551-e554. e555.

35. Fytagoridis A, Sandvik U, Astrom M, Bergenheim T, Blomstedt P. Long term follow-up of deep brain stimulation of the caudal zona incerta for essential tremor. J Neurol Neurosurg Psychiatry. 2012; 83(3):258-262.

36. Sandvik U, Hariz GM, Blomstedt P. Quality of life following DBS in the caudal zona incerta in patients with essential tremor. Acta Neurochir. 2012;154(3):495-499.

37. Nahab FB, Peckham E, Hallett M. Essential tremor, deceptively simple... . Pract Neurol. 2007;7(4):222-233.

38. Macchi G, Jones EG. Toward an agreement on terminology of nuclear and subnuclear divisions of the motor thalamus. J Neurosurg. 1997;86(4):670-685.

39. Strick PL. Anatomical analysis of ventrolateral thalamic input to primate motor cortex. J Neurophysiol. 1976;39(5):1020-1031. 
40. Asanuma C, Thach WT, Jones EG. Distribution of cerebellar terminations and their relation to other afferent terminations in the ventral lateral thalamic region of the monkey. Brain Res. 1983;286(3):237-265.

41. Klein JC, Barbe MT, Seifried C, et al. The tremor network targeted by successful VIM deep brain stimulation in humans. Neurology. 2012;78(11):787-795.

42. Flora ED, Perera CL, Cameron AL, Maddern GJ. Deep brain stimulation for essential tremor: a systematic review. Mov Disord. 2010;25(11): 1550-1559.

43. Papavassiliou E, Rau G, Heath S, et al. Thalamic deep brain stimulation for essential tremor: relation of lead location to outcome. Neurosurgery. 2004;54(5):1120-1129; discussion 1129-1130.

44. Heise CE, Mitrofanis J. Evidence for a glutamatergic projection from the zona incerta to the basal ganglia of rats. J Comp Neurol. 2004;468(4): 482-495.

45. Mitrofanis J, Mikuletic L. Organisation of the cortical projection to the zona incerta of the thalamus. J Comp Neurol. 1999;412(1):173-185.

46. Xie T, Bernard J, Warnke P. Post subthalamic area deep brain stimulation for tremors: a mini-review. Transl Neurodegener. 2012;1(1):20.

47. Roger M, Cadusseau J. Afferents to the zona incerta in the rat: a combined retrograde and anterograde study. J Comp Neurol. 1985;241(4): 480-492.

48. Shammah-Lagnado SJ, Negrao N, Ricardo JA. Afferent connections of the zona incerta: a horseradish peroxidase study in the rat. Neuroscience. 1985;15(1):109-134.

49. Watanabe K, Kawana E. The cells of origin of the incertofugal projections to the tectum, thalamus, tegmentum and spinal cord in the rat: a study using the autoradiographic and horseradish peroxidase methods Neuroscience. 1982;7(10):2389-2406.

50. Power BD, Mitrofanis J. Ultrastructure of afferents from the zona incerta to the posterior and parafascicular thalamic nuclei of rats. J Comp Neurol. 2002;451(1):33-44.

51. Power BD, Mitrofanis J. Specificity of projection among cells of the zona incerta. J Neurocytol. 1999;28(6):481-493.

52. Power BD, Mitrofanis J. Evidence for extensive inter-connections within the zona incerta in rats. Neurosci Lett. 1999;267(1):9-12.
53. Bartho P, Freund TF, Acsady L. Selective GABAergic innervation of thalamic nuclei from zona incerta. Eur J Neurosci. 2002;16(6): 999-1014.

54. Lin CS, Nicolelis MA, Schneider JS, Chapin JK Jr. GABAergic pathway from zona incerta to neocortex: clarification. Science. 1991; 251(4998):1162.

55. Nicolelis MA, Chapin JK, Lin RC. Development of direct GABAergic projections from the zona incerta to the somatosensory cortex of the rat. Neuroscience. 1995;65(2):609-631.

56. Plaha P, Khan S, Gill SS. Bilateral stimulation of the caudal zona incerta nucleus for tremor control. J Neurol Neurosurg Psychiatry. 2008;79(5):504-513.

57. Blomstedt P, Sandvik U, Hariz MI, et al. Influence of age, gender and severity of tremor on outcome after thalamic and subthalamic DBS for essential tremor. Parkinsonism Relat Disord. 2011;17(8): 617-620.

58. Hamel W, Herzog J, Kopper F, et al. Deep brain stimulation in the subthalamic area is more effective than nucleus ventralis intermedius stimulation for bilateral intention tremor. Acta Neurochir. 2007;149(8): 749-758; discussion 758.

59. Fields JA, Troster AI, Woods SP, et al. Neuropsychological and quality of life outcomes 12 months after unilateral thalamic stimulation for essential tremor. J Neurol Neurosurg Psychiatry. 2003;74(3):305-311.

60. Fytagoridis A, Sjöberg RL, Åström M, Fredricks A, Nyberg L, Blomstedt P. Effects of deep brain stimulation in the caudal zona incerta on verbal fluency. Stereotact Funct Neurosurg. 2013;91(1):24-29.

61. Hariz GM, Blomstedt P, Koskinen LO. Long-term effect of deep brain stimulation for essential tremor on activities of daily living and health-related quality of life. Acta Neurol Scand. 2008;118(6): 387-394.

62. Bahgat D, Magill ST, Berk C, McCartney S, Burchiel KJ. Thalamotomy as a treatment option for tremor after ineffective deep brain stimulation. Stereotact Funct Neurosurg. 2013;91(1):18-23.
Neuropsychiatric Disease and Treatment

\section{Publish your work in this journal}

Neuropsychiatric Disease and Treatment is an international, peerreviewed journal of clinical therapeutics and pharmacology focusing on concise rapid reporting of clinical or pre-clinical studies on a range of neuropsychiatric and neurological disorders. This journa is indexed on PubMed Central, the 'PsycINFO' database and CAS.

\section{Dovepress}

The manuscript management system is completely online and includes a very quick and fair peer-review system, which is all easy to use. Visit http://www.dovepress.com/testimonials.php to read real quotes from published authors. 